\title{
DEXAMETHASONE USE IN MANAGEMENT OF COVID19:
}

\author{
A REVIEW \\ Samer Mohammed \\ College of Pharmacy, University of Baghdad, Iraq \\ *Corresponding author: samer.jameel@copharm.uobaghdad.edu.iq
}

\begin{abstract}
The lack of active 2019 coronavirus disease (COVID-19) pandemic treatment creates a challenge for researchers and scientists to find the most appropriate treatment for this disease. Dexamethasone, according to the findings of the RECOVERY clinical trial, declared mid-June 2020 in print media was one of those therapies. Although the results from retrospective studies are not strongly supportive of corticosteroid routine use in COVID-19 despite the signals for some benefits, the dedicated RECOVERY trial found a significant reduction in death with dexamethasone only in severe cases on a ventilator or moderate cases on supplemental oxygen therapy nevertheless, no benefit observed in mild to moderate cases requiring no oxygen. More studies are still necessary to substantiate conclusive use with dexamethasone in COVID-19. This narrative review attempts to summarize all available shreds of evidence from previously published research articles on the use of dexamethasone in COVID-19 pandemic treatment.
\end{abstract}

Keywords: COVID-19, Dexamethasone, Acute Respiratory Distress Syndrome, Randomized controlled trial, Steroids, pandemic. 


\section{Introduction}

The absence of efficient treatment for the 2019 pandemic of persistent coronavirus disease (COVID19) creates a challenge for all specialists and scientists to find an efficient treatment for this disease (Beigel et al., 2020). One of these potential treatment options was dexamethasone corresponding to a print media announcement in mid-June 2020 (along with consequent report2) from the RECOVERY clinical trial(“Dexamethasone in Hospitalized Patients with Covid-19 — Preliminary Report," 2020a). The U.K. Guidelines Released The use of glucocorticoids in hospitalized COVID-19 patients was proposed by chief medical officers and by the National Institutes of Health in the United States (National Institutes of Health. 2020). As well known, dexamethasone is regarded as essential medicines according to the World Health Organization (WHO) and readily available worldwide at affordable low cost and long history of safety (National Institutes of Health, 2020). Dexamethasone is a synthetic corticosteroid with a more significant activity of immunosuppression (30 times) and a longer duration of action (2-3days) than natural cortisone (Beigel et al., 2020). The objective of this narrative review is to summarize all available data from previously published studies concerning the use of dexamethasone in the treatment of the COVID-19 pandemic.

\section{Methods}

A systematic and comprehensive search using specific keywords "Dexamethasone," "Corticosteroids," "Adult Respiratory Distress Syndrome," "COVID-19" from PubMed, Google Scholar, and Cochrane Library electronic database was conducted until September 31, 2020. All the papers were subsequently thoroughly investigated and presented in the text.

The rationale of the use of dexamethasone in COVID-19:

According to WHO, the majority of hospitalized COVID-19 patients developing acute respiratory distress syndrome (ARDS) (Grasselli et al., 2020), and up to $12 \%$ of those patients required invasive mechanical ventilation (Docherty et al., 2020; Richardson et al., 2020)The pulmonary histological examination of patients with COVID-19 showed diffuse alveolar damage with hyaline membranes (Ackermann et al., 2020) Additionally, a multiorgan failure may occur because of an uncontrolled inflammatory state (Moore et al., 2020)(Qin et al., 2020). Consequently, Corticosteroids can play a crucial role in managing these complications associated with hospitalized COVID-19 patients(Rhen \& Cidlowski, 2005).

Glucocorticoids have previously been used effectively in COVID-19-related viral infections, such as "SARS, Middle East Respiratory Syndrome (MERS), severe influenza, and community-acquired pneumonia"(Arabi et al.,2018). Nevertheless, due to the paucity of sufficient data from large randomized, controlled trials, the evidence to endorse or discourage the use of glucocorticoids for these 
disorders has been weak(Arabi et al.2018) (Lansbury et al., 2020). The findings obtained from animal models or even small clinical trials of coronaviruses other than COVID 19 were confusing(Nelson Lee et al., 2003). While some therapeutic benefits were observed from prior research measuring the efficacy of glucocorticoid therapy in the 2003 Coronavirus Severe Acute Respiratory Syndrome spread (SARS-CoV) (Nelson Lee et al., 2003).

On the other hand, recent glucocorticoid therapy meta-analysis for Middle East respiratory syndrome coronavirus (MERS-CoV), SARS-CoV, and SARS-CoV-2 has elicited caution, referring to delays in viral clearance and lack of evidence for improved patient outcomes( $\mathrm{Li}$.H et al., 2020.). In line with these mixed findings, Many recommendations for the treatment of hospitalized COVID-19 patients have suggested that glucocorticoids have either been contraindicated or not prescribed due to the lack of credible evidence from large-scale randomized clinical trials (Dagens et al., 2020.). However, dexamethasone and methylprednisolone have been suggested for severe cases(Zhao et al., 2020.). One research evaluated the mortality effect of dexamethasone in hospitalized patients with severe respiratory complications of COVID-19 and concluded that dexamethasone decreased mortality by onethird in ventilator patients and one-fifth in oxygen-only patients. However, this advantage was not seen in milder disease patients who did not require respiratory intervention (University of Oxford, 2020).

\section{Benefits of dexamethasone use in COVID-19:}

We need to outline some main clinical characteristics of this disease to explain the potential benefits of dexamethasone in COVID-19. The vital pathophysiological features of severe COVID-19 cases are acute pneumonia with substantial radiological opacity and diffuse alveolar injury, inflammatory infiltrates, and microvascular thrombosis(Carsana et al., 2020.). Inflammation caused by the release of inflammatory chemokines, such as tumor necrosis factor-alpha(TNF-alpha), released by immune cells such as neutrophils, has led to pneumonia. (Ware \& Matthay, 2000). acute respiratory distress syndrome (ARDS ) is caused by fluid accumulation and pneumonia(Ware \& Matthay, 2000).

Severe condition of COVID-19 represents about $15-30 \%$ of patients that may result in ARDS that is associated with a mortality rate of nearly $65 \%$ (X. Li \& Ma, 2020). The main contributor to mortality in positive COVID-19 patients is ARDS. (Ware \& Matthay, 2000) by causing shock that leads to multiple organ failure followed by the death of the patients(C. Huang et al., 2020).

Using dexamethasone in COVID-19 infections is mainly because of its anti-inflammatory action comprising cytokine storm, which leads to disease aggravation(Shang et al., 2020) and decreased mortality in acutely ill COVID-19 illnesses(Theoharides \& Conti, 2020). In hospitalized patients needing supplemental oxygen or mechanical ventilation due to the use of dexamethasone, reduced mortality was demonstrated by cumulative results from randomized clinical trials. ("Dexamethasone in Hospitalized Patients with Covid-19 - Preliminary Report," 2020b) Nevertheless, no proven improvements were noticed in COVID_19 patients with mild or even moderate disease states or any 
hospitalized COVID-19 patients who did not require oxygen therapy or mechanical ventilation ( Ledford et al.,2020.)

In patients with comorbid conditions, including chronic respiratory disorders, cardiovascular and cerebrovascular diseases, diabetes, and hypertension, who have a greater risk of developing severe COVID-19 with ARD or multiorgan failure, the protective effect of dexamethasone from a cytokine storm is frequently observed(I. Huang et al.,2020). Besides cytokine storm suppression, dexamethasone is also indicated in COVID-19 patients to treat severe immune thrombocytopenic purpura(Bomhof et al., 2020).

Mechanism of action:

It is proposed that dexamethasone's anti-inflammatory activity is likely to mitigate the cytokine storm caused by COVID-19 infection, which protects the lungs and ultimately lives and needs thorough investigations(Patel et al., 2020). On the other hand, dexamethasone suppresses lymphocytes' actions that play a crucial role in coronavirus suppression. Therefore, it is necessary to avoid corticosteroids in patients with COVID-19 infections in the initial stable or even in mild-to-moderate conditions (Marinella, 2020). Inhibition of dexamethasone's pro-inflammatory state occurs by inhibiting cytokines such as interleukin type 1 (IL-1), TNF, and interleukin type 6( IL-6), inhibiting chemokines, or other soluble mediators like leukotrienes, prostaglandin E2 (Cain \& Cidlowski, 2020).

COVID-19 has recently been subdivided into two phases: in the early phase, virus pathology dominates; and in the later phase, immunopathology drives disease. (Cain \& Cidlowski, 2020). Perhaps it is not unexpected in this way of thinking about COVID-19 that the offer of dexamethasone in the RECOVERY study showed minimal benefit when used in patients whose disease had not progressed to a level requiring oxygen therapy or ventilation; the immunosuppressive effects of glucocorticoids at this phase of the illness may have been probable and may obstructing antiviral responses(Cain \& Cidlowski, 2020). The predominant influential role of dexamethasone appeared clearly in the hyperinflammatory phase of COVID-19 by interrupting the inflammatory cycle(Cain \& Cidlowski, 2020).

Likewise, in one study's preliminary report specifically concludes, There was no obvious sign that dexamethasone offered any advantage to patients who did not receive respiratory care. ("Dexamethasone in Hospitalized Patients with Covid-19 - Preliminary Report," 2020b). In viral severe respiratory infections, the beneficial role of glucocorticoids depends on selecting the correct dose. High doses can be associated with many complications, and the right time of administration as such care is provided when regulation of viral replication is crucial. Inflammation is limited (Nelson Lee et al., 2003). The dexamethasone dose in COVID-19 patients was chosen based on several clinical trials that used dexamethasone to treat Non-COVID-19 ARDS patients (Theoharides \& Conti, 2020). All earlier 
evidence concluded that large doses of corticosteroids equal to $30 \mathrm{mg} / \mathrm{d}$ of dexamethasone in viral pneumonia might be correlated with adverse effects (Cao et al., 2016). Accordingly, dexamethasone was used at a low dose rate (6 mg/day) in the several case series that evaluates the use of dexamethasone in COVID-19(“Dexamethasone in Hospitalized Patients with Covid-19 — Preliminary Report," 2020a).

\section{Complications:}

Dexamethasone has shown that it can reduce $T$ cells' defensive function, inhibit the production of antibodies from B-cells, and prevent a macrophage clearance process, which potentially leads to higher viral plasma levels and a greater risk of secondary infection. (Theoharides \& Conti, 2020). Additionally, slower clearing of viral RNA was also observed in SARS, MERS, and influenza patients treated with systemic glucocorticoids, but those findings' clinical significance is uncertain (Lee et al., 2003). Potentially severe, but preventable, less common adverse effects such as Strongyloides hyper infection or dissemination syndrome (hyperinfection) could be difficult to recognize by many clinicians (Krolewiecki et al., 2019).

Most of these fatal iatrogenic adverse effects are asymptomatic and independent of dose or duration of treatment and mainly appeared with the use of an immunosuppressive drug in patients with unrecognized chronic infection(Requena-Méndez et al., 2017). Correspondingly, in cases with COVID19 who are at risk for strongyloidiasis and are candidates for treatment with dexamethasone, physicians and health care systems should consider adopting a plan to avoid hyper infection syndrome(Stauffer et al.,2020).

As well-known, hyperglycemia can last more than 24 hours after a given dose of dexamethasone. But a short steroid course in most of the COVID-19 studies is less likely to have triggered steroid-induced hyperglycemia or even worsened glycemic control of pre-existing diabetes patients. Even so, every therapist must be attentive to the expected deterioration in hyperglycemia using corticosteroids in COVID-19 patients and take some corrective action to deal with it (Singh et al., 2020).

in order to avoid some serious side effects of corticosteroids in patients with COVID-19, immunoglobulins (IV-IG) and Interferon-beta (IFN- $\beta$ ) have been administered simultaneously in some clinical trials to test the hypothesis that early administration of dexamethasone along with IV-IG and IFN- $\beta$ could or may not minimize the consequences of cytokine storm in critically ill patients with COVID19 (Sibila et al., 2008). Since dexamethasone is readily accessible and inexpensive and can be obtained without a prescription, some individuals can tend to self-medicate. Dexamethasone is, in fact, not an antiviral, nor is it a definite cure for COVID19, so it can weaken their immunity and lead to an increase in susceptibility to the viral and other infections in healthy individuals (Lim \& Pranata, 2020). Besides, dexamethasone costs may rise significantly and become difficult for those who need it or even 
sell it at highly overestimated rates. In such unanticipated cases, healthcare professionals may turn to other corticosteroids, such as methylprednisolone, as an option for patients in need.(Lim \& Pranata, 2020). For that, The WHO has also urged pharmaceutical companies to ramp up dexamethasone production, as demand is expected to increase (WHO Director-General's opening remarks at the media briefing on COVID-19 - 22 June 2020).

Another issue associated with dexamethasone was the limitations in health systems in any context that could affect the intervention's effectiveness and change the risk-benefit balance. A reduced ability to monitor blood sugar levels or detect co-morbidities where, for example, steroids are contraindicated can have adverse effects. Similarly, in the absence of critical care facilities and perfectly qualified staff, steroids can have an even more significant mortality impact than benefits that could turn COVID-19's management (Brotherton et al., 2020).

\section{Clinical trial outlines}

Although many previous trials assessed the role of corticosteroids for non-COVID-19 ARDS with conflicting results however only a few trials evaluate the effect of corticosteroids or specifical dexamethasone in COVID-19(Steinberg et al., 2006; Villar et al., 2020). Most of these studies were cohort-limited and had a high degree of heterogeneity about steroid selection, dose, timing, and coprescribed broad-spectrum antibiotics and antivirals(Guan et al., 2020; Liu et al.,2020; Wu et al.,2020; Zhou et al., 2020). Only one study clearly measured the steroid benefits related to their action(Wu et al.,2020); others found little benefit in acute pulmonary injury or ARDS patients, regardless of steroid administration timing. Indeed, corticosteroid therapy has also been shown to improve the body's time for viral excretion (Ling et al., 2020).

The most relevant study was the randomized assessment of the COVID-19 treatment (RECOVERY) trial (open-label, controlled study), which involved 6,425 patients randomized to $6 \mathrm{mg}$ per day of dexamethasone or standard treatment. Overall, dexamethasone resulted in a $2.8 \%$ absolute reduction in mortality $(22.9 \%$ vs $25.7 \%$ for standard care group; 0.83 [95 \% Cl, $0.75-0.93$ ] age-adjusted rate ratio). The benefit was greatest for patients with invasive mechanical ventilation at randomization, with a mortality rate of $29.3 \%$ for dexamethasone vs. $41.4 \%$ for standard care (rate ratio, 0.64 [95\% Cl, 0.51 0.81]) (“Dexamethasone in Hospitalized Patients with Covid-19 — Preliminary Report," 2020b). 


\section{Conclusion}

Still, there have been enduring debates regarding the role of corticosteroids in treating severe infections. The pandemic was a powerful stimulus that resolved this dispute in clinical science. Dexamethasone may have a protective effect on serious COVID-19 ARDS infections, as clearly appeared in the Recovery trial. However, large-scale ongoing clinical trials may shed light on the clinical efficacy of corticosteroids in COVID-19 conditions. The exploration of the dose-dependent reaction of dexamethasone in extreme COVID-19 patients is warranted by further research. Clinical studies have shown that treatment with low-dose dexamethasone supplements endogenous cortisol production to reduce immunopathology associated with COVID-19 while preventing high-dose glucocorticoid's adverse effects therapy.

\section{Conflicts of Interest:}

The authors declare no conflicts of interest.

\section{References}

- Arabi, Y. M., Mandourah, Y., Al-Hameed, F., Sindi, A. A., Almekhlafi, G. A., Hussein, M. A., ... \& Fowler, R. A. (2018). Corticosteroid therapy for critically ill patients with Middle East respiratory syndrome. American journal of respiratory and critical care medicine, 197(6), 757767.

- Ackermann, M., Verleden, S. E., Kuehnel, M., Haverich, A., Welte, T., Laenger, F., Vanstapel, A., Werlein, C. M. D., Stark, H., Tzankov, A., Li, W. W., Li, V. W., Mentzer, S. J., \& Jonigk, D. (2020). Pulmonary vascular endothelialitis, thrombosis, and angiogenesis in Covid-19. New England Journal of Medicine, 383(2), 120-128. https://doi.org/10.1056/NEJMoa2015432

- Beigel, J. H., Tomashek, K. M., Dodd, L. E., Mehta, A. K., Zingman, B. S., Kalil, A. C., Hohmann, E., Chu, H. Y., Luetkemeyer, A., Kline, S., Lopez de Castilla, D., Finberg, R. W., Dierberg, K., Tapson, V., Hsieh, L., Patterson, T. F., Paredes, R., Sweeney, D. A., Short, W. R., ... Lane, H. C. (2020). Remdesivir for the Treatment of Covid-19 - Preliminary Report. New England Journal of Medicine. https://doi.org/10.1056/nejmoa2007764

- Bomhof, G., Mutsaers, P. G. N. J., Leebeek, F. W. G., Boekhorst, P. A. W., Hofland, J., Croles, F. N., \& Jansen, A. J. G. (2020). COVID-19-associated immune thrombocytopenia. British Journal of Haematology, 190(2), e61-e64. https://doi.org/10.1111/bjh.16850

- Brotherton, H., Usuf, E., Nadjm, B., Forrest, K., Bojang, K., Samateh, A. L., Bittaye, M., Roberts, C. A., d'Alessandro, U., \& Roca, A. (2020). Dexamethasone for COVID-19: data needed from randomised clinical trials in Africa. In The Lancet Global Health (Vol. 8, Issue 9, pp. e1125e1126). Elsevier Ltd. https://doi.org/10.1016/S2214-109X(20)30318-1

- Cain, D. W., \& Cidlowski, J. A. (2020). After 62 years of regulating immunity, dexamethasone meets COVID-19. Nature Reviews Immunology, 20(10), 587-588.

- Cao, B., Gao, H., Zhou, B., Deng, X., Hu, C., Deng, C., Lu, H., Li, Y., Gan, J., Liu, J., Li, H., Zhang, Y., Yang, Y., Fang, Q., Shen, Y., Gu, Q., Zhou, X., Zhao, W., Pu, Z., ... Li, L. (2016). Adjuvant corticosteroid treatment in adults with influenza a (H7N9) viral pneumonia. Critical Care Medicine, 44(6), e318-e328. https://doi.org/10.1097/CCM.0000000000001616

- Carsana, L., Sonzogni, A., Nasr, A., ... R. R.-T. L. I. (2020). Pulmonary post-mortem findings in a series of COVID-19 cases from northern Italy: a two-centre descriptive study. Elsevier. $\begin{array}{llll}\text { Retrieved October 2020, from } & \end{array}$ https://www.sciencedirect.com/science/article/pii/S1473309920304345

- Dagens, A., Sigfrid, L., Cai, E., Lipworth, S., bmj, V. C. (2020). Scope, quality, and inclusivity of clinical guidelines produced early in the covid-19 pandemic: rapid review. Bmj.Com. Retrieved October 7, 2020, from https://www.bmj.com/content/369/bmj.m1936.full

- Dexamethasone in Hospitalized Patients with Covid-19 - Preliminary Report. (2020a). New England Journal of Medicine, 1-11. https://doi.org/10.1056/nejmoa2021436. 
- Docherty, A. B., Harrison, E. M., Green, C. A., Hardwick, H. E., Pius, R., Norman, L., ... \& Semple, M. G. (2020). Features of 20133 UK patients in hospital with covid-19 using the ISARIC WHO Clinical Characterisation Protocol: prospective observational cohort study. bmj, 369. doi: https://doi.org/10.1136/bmj.m1985 (Published 22 May 2020)

- Grasselli, G., Zangrillo, A., Zanella, A., Antonelli, M., Cabrini, L., Castelli, A., ... \& Pesenti, A. (2020). Baseline characteristics and outcomes of 1591 patients infected with SARS-CoV-2 admitted to ICUs of the Lombardy Region, Italy. Jama, 323(16), 1574-1581.

- Guan, W., Ni, Z., Hu, Y., Liang, W., Ou, C., He, J., Liu, L., Shan, H., Lei, C., Hui, D. S. C., Du, B., Li, L., Zeng, G., Yuen, K. Y., Chen, R., Tang, C., Wang, T., Chen, P., Xiang, J., ... Zhong, N. (2020). Clinical characteristics of coronavirus disease 2019 in China. New England Journal of Medicine, 382(18), 1708-1720. https://doi.org/10.1056/NEJMoa2002032

- Huang, C., Wang, Y., Li, X., Ren, L., Zhao, J., Hu, Y., ... \& Cao, B. (2020). Clinical features of patients infected with 2019 novel coronavirus in Wuhan, China. The lancet, 395(10223), 497506.

- Huang, I., Lim, M. A., \& Pranata, R. (2020). Diabetes mellitus is associated with increased mortality and severity of disease in COVID-19 pneumonia-a systematic review, meta-analysis, and meta-regression. Diabetes \& Metabolic Syndrome: Clinical Research \& Reviews. Volume 14, Issue 4, Pages 395-403

- Krolewiecki, A., \& Nutman, T. B. (2019). Strongyloidiasis: a neglected tropical disease. Infectious Disease Clinics, 33(1), 135-151.

- Lansbury, L. E., Rodrigo, C., Leonardi-Bee, J., Nguyen-Van-Tam, J., \& Shen Lim, W. (2020). Corticosteroids as Adjunctive Therapy in the Treatment of Influenza. Critical Care Medicine, 48(2), e98-e106. https://doi.org/10.1097/CCM.0000000000004093

- Lee, N., Chan, K. A., Hui, D. S., Ng, E. K., Wu, A., Chiu, R. W., ... \& Lo, Y. D. (2004). Effects of early corticosteroid treatment on plasma SARS-associated Coronavirus RNA concentrations in adult patients. Journal of clinical virology, 31(4), 304-309.

- Lee, N., Chan, P. K., Hui, D. S., Rainer, T. H., Wong, E., Choi, K. W., ... \& Sung, J. J. (2009). Viral loads and duration of viral shedding in adult patients hospitalized with influenza. The Journal of infectious diseases, 200(4), 492-500.

- Lee, Nelson, Hui, D., Wu, A., Chan, P., Cameron, P., Joynt, G. M., Ahuja, A., Yung, M. Y., Leung, C. B., To, K. F., Lui, S. F., Szeto, C. C., Chung, S., \& Sung, J. J. Y. (2003). A major outbreak of severe acute respiratory syndrome in Hong Kong. New England Journal of Medicine, 348(20), 1986-1994. https://doi.org/10.1056/NEJMoa030685

- Li, H., Chen, C., Hu, F., Wang, J., Zhao, Q., Gale, R. P., \& Liang, Y. (2020). Impact of corticosteroid therapy on outcomes of persons with SARS-CoV-2, SARS-CoV, or MERS-CoV infection: a systematic review and meta-analysis. Leukemia, 1-9. 34, pages1503-1511

- Li, X., \& Ma, X. (2020). Acute respiratory failure in COVID-19: is it "typical" ARDS?. Critical Care, 24, 1-5.

- Lim, M. A., \& Pranata, R. (2020). Worrying situation regarding the use of dexamethasone for COVID-19. In Therapeutic Advances in Respiratory Disease (Vol. 14). SAGE Publications Ltd. https://doi.org/10.1177/1753466620942131

- $\quad$ Ling, Y., Xu, S. B., Lin, Y. X., Tian, D., Zhu, Z. Q., Dai, F. H., ... \& Lu, H. Z. (2020). Persistence and clearance of viral RNA in 2019 novel coronavirus disease rehabilitation patients. Chinese medical journal. 133(9): 1039-1043.

- Liu, K., Fang, Y. Y., Deng, Y., Liu, W., Wang, M. F., Ma, J. P., ... \& Liu, H. G. (2020). Clinical characteristics of novel coronavirus cases in tertiary hospitals in Hubei Province. Chinese medical journal. 133(9): 1025-1031.

- Ledford, H. (2020). Coronavirus breakthrough: dexamethasone is first drug shown to save lives. Nature, 582(7813), 469-469.

- Marinella, M. A. (2020). Routine antiemetic prophylaxis with dexamethasone during COVID-19: Should oncologists reconsider? In Journal of Oncology Pharmacy Practice (Vol. 26, Issue 6, pp. 1482-1485). SAGE Publications Ltd. https://doi.org/10.1177/1078155220931921

- Moore, J. B., \& June, C. H. (2020). Cytokine release syndrome in severe COVID-19. Science, 368(6490), 473-474.

- National Institutes of Health. (2020). Coronavirus disease 2019 (COVID-19) treatment guidelines. 
- Patel, S. K., Saikumar, G., Rana, J., Dhama, J., Yatoo, M. I., Tiwari, R., Rodríguez-Morales, A. J., \& Dhama, K. (2020). Dexamethasone: A boon for critically ill COVID-19 patients? In Travel Medicine and Infectious Disease (Vol. 37, p. 101844). Elsevier USA. https://doi.org/10.1016/j.tmaid.2020.101844

- $\quad$ Qin, C., Zhou, L., Hu, Z., Zhang, S., Yang, S., Tao, Y., Xie, C., Ma, K., Shang, K., Wang, W., \& Tian, D. S. (2020). Dysregulation of Immune Response in Patients With Coronavirus 2019 (COVID-19) in Wuhan, China. Clinical Infectious Diseases: An Official Publication of the Infectious Diseases Society of America, 71(15), 762-768. https://doi.org/10.1093/cid/ciaa248

- Requena-Méndez, A., Buonfrate, D., Gomez-Junyent, J., Zammarchi, L., Bisoffi, Z., \& Muñoz, J. (2017). Evidence-based guidelines for screening and management of strongyloidiasis in nonendemic countries. In American Journal of Tropical Medicine and Hygiene (Vol. 97, Issue 3, pp. 645-652). American Society of Tropical Medicine and Hygiene. https://doi.org/10.4269/ajtmh.16-0923

- Rhen, T., \& Cidlowski, J. A. (2005). Antiinflammatory Action of Glucocorticoids - New Mechanisms for Old Drugs. New England Journal of Medicine, 353(16), 1711-1723. https://doi.org/10.1056/NEJMra050541

- Richardson, S., Hirsch, J. S., Narasimhan, M., Crawford, J. M., McGinn, T., Davidson, K. W., Barnaby, D. P., Becker, L. B., Chelico, J. D., Cohen, S. L., Cookingham, J., Coppa, K., Diefenbach, M. A., Dominello, A. J., Duer-Hefele, J., Falzon, L., Gitlin, J., Hajizadeh, N., Harvin, T. G., ... Zanos, T. P. (2020). Presenting Characteristics, Comorbidities, and Outcomes Among 5700 Patients Hospitalized With COVID-19 in the New York City Area. JAMA, 323(20), 2052. https://doi.org/10.1001/jama.2020.6775

- Shang, L., Zhao, J., Hu, Y., Du, R., \& Cao, B. (2020). On the use of corticosteroids for 2019nCoV pneumonia. In The Lancet (Vol. 395, Issue 10225, pp. 683-684). Lancet Publishing Group. https://doi.org/10.1016/S0140-6736(20)30361-5

- Sibila, O., Luna, C. M., Agustí, C., Baquero, S., Gando, S., Patrón, J. R., Morato, J. G., Absif, R., Bassie, N., \& Torres, A. (2008). Effects of glucocorticoids in ventilated piglets with severe pneumonia. European Respiratory Journal, 32(4), 1037-1046. https://doi.org/10.1183/09031936.00009208

- Singh, A. K., Majumdar, S., Singh, R., \& Misra, A. (2020). Role of corticosteroid in the management of COVID-19: A systemic review and a Clinician's perspective. Diabetes and Metabolic Syndrome: Clinical Research and Reviews, 14(5), 971-978. https://doi.org/10.1016/j.dsx.2020.06.054

- Stauffer, W., Alpern, J., Jama, P. W. (2020). COVID-19 and Dexamethasone: A Potential Strategy to Avoid Steroid-Related Strongyloides Hyperinfection. Jamanetwork.Com. Retrieved October 7, 2020, from https://jamanetwork.com/journals/jama/article-abstract/2769100

- Steinberg, K. P., Hudson, L. D., Goodman, R. B., Hough, C. L., Lanken, P. N., Hyzy, R., Thompson, B. T., \& Ancukiewicz, M. (2006). Efficacy and safety of corticosteroids for persistent acute respiratory distress syndrome. New England Journal of Medicine, 354(16), 1671-1684. https://doi.org/10.1056/NEJMoa051693

- Theoharides, T. C., \& Conti, P. (2020). Dexamethasone for COVID-19? Not so fast. Journal of Biological Regulators and Homeostatic Agents, 34(3), 10-13. https://doi.org/10.23812/20EDITORIAL_1-5

- University of Oxford. (2020). Low-cost dexamethasone reduces death by up to one third in hospitalised patients with severe - The RECOVERY Trial. Oxford, 1-4.

- Villar, J., Ferrando, C., Martínez, D., Ambrós, A., Muñoz, T., Soler, J. A., ... \& Soro, M. (2020). Dexamethasone treatment for the acute respiratory distress syndrome: a multicentre, randomised controlled trial. The Lancet Respiratory Medicine, 8(3), 267-276.

- Ware, L. B., \& Matthay, M. A. (2000). The Acute Respiratory Distress Syndrome. New England Journal of Medicine, 342(18), 1334-1349. https://doi.org/10.1056/NEJM200005043421806

- WHO Director-General's opening remarks at the media briefing on COVID-19-22 June 2020. Retrieved October 7, 2020, from https://www.who.int/dg/speeches/detail/who-director-generals-opening-remarks-at-the-media-briefing-on-covid-19---22-june-2020

- Wu, C., Chen, X., Cai, Y., Zhou, X., Xu, S., Huang, H., ... \& Song, Y. (2020). Risk factors associated with acute respiratory distress syndrome and death in patients with coronavirus disease 2019 pneumonia in Wuhan, China. JAMA internal medicine. 180(7):934-943. doi:10.1001/jamainternmed.2020.0994. 
- Zhao, J. P., Hu, Y., Du, R. H., Chen, Z. S., Jin, Y., Zhou, M., ... \& Cao, B. (2020). Expert consensus on the use of corticosteroid in patients with 2019-nCoV pneumonia. Zhonghua jie he he hu xi za zhi= Zhonghua jiehe he huxi zazhi= Chinese journal of tuberculosis and respiratory diseases, 43(3), 183-184.

- Zhou, F., Yu, T., Du, R., Fan, G., Liu, Y., Liu, Z., Xiang, J., Wang, Y., Song, B., Gu, X., Guan, L., Wei, Y., Li, H., Wu, X., Xu, J., Tu, S., Zhang, Y., Chen, H., \& Cao, B. (2020). Clinical course and risk factors for mortality of adult inpatients with COVID-19 in Wuhan, China: a retrospective cohort study. The Lancet, 395(10229), 1054-1062. https://doi.org/10.1016/S01406736(20)30566-3 